\title{
Theories of Mind and 'The Commonsense View'
}

\author{
CYNTHIA MACDONALD
}

\begin{abstract}
It is widely believed that people are sometimes directly aware of their own psychological states and consequently better placed than others to know what the contents of those states are. This ('commonsense') view has been challenged by Alison Gopnik. She claims that experimental evidence from the behaviour of 3- and 4-yearold children both supports the theory theory and shows that the belief in direct and privileged knowledge of one's own intentional states is an illusion. I argue (1) that the experimental evidence is not inconsistent with the commonsense view and that Gopnik's central thesis assumes a particularly crude perceptual account of self-knowledge to which that view is not committed, and (2) that the commonsense view is neutral as between the theory theory and other theories of mind.
\end{abstract}

It is widely believed that people are, at least sometimes, directly or immediately aware of their own psychological states and so better placed than others to know what the contents of those states are. This belief is said to be a dictate of commonsense, or folk, psychology. We might call it the commonsense view'. ${ }^{1}$ Commonsense tells us that we, as subjects of our own psychological states, not only know them, but sometimes know them in a direct and privileged sort of way.

A number of views about people depend on this assumption of privileged access. The liberal conception in political philosophy, for example, assumes that subjects are in a better position than others to know their own desires. ${ }^{2}$

Versions of this paper were read at the Queen's University, Belfast and at the Annual Australasian Association of Philosophy Conference, December, 1999. I am grateful to the audiences for very helpful comments. I am also indebted to Tim Bayne, Dorothy Grover, and especially Martin Davies, Philip Gerrans, and Graham Macdonald, from whose comments and discussion I have profited greatly.

Address for correspondence: Department of Philosophy, University of Canterbury, Private Bag 4800, Christchurch, New Zealand.

Email: c.macdonald@phil.canterbury.ac.nz

1 This is Alison Gopnik's (1993) term.

2 The classic example is Mill, who says

But neither one person, nor any number of persons, is warranted in saying to another human creature...that he shall not do with his life for his own benefit what he chooses to do with it. .... The interest which any other person...can have in it, is trifling... and altogether indirect: while, with respect to his own feelings and circumstances, the most ordinary man or woman has means of knowledge immeasurably surpassing those that can be possessed by any one else (1989, p. 76).

By 'feelings' Mill here clearly means 'desires'. 
And the conception of agents as responsible for their actions presumes that they know, in a way that others do not, what their intentions are in so acting. These views assume, as commonsense does, that there is an asymmetry between self-knowledge and knowledge of others in that the former, unlike the latter, is at least sometimes authoritative.

I think that commonsense is right about this. When I say to a friend, 'I'm going to the bank', I know, in a way that my friend does not, what I mean by 'bank'. I don't need to wonder, as my friend might, whether I'm going fishing or going to get some cash. When I stammer over a word, I know which word I am struggling to utter, in a way in which you, listening to me, do not. When I look at the clock and think to myself, 'it's time to get moving', I know what I am thinking in a way that my audience does not. I somehow know it 'directly' or 'immediately'. Such terms as 'direct' and 'immediate' may be vague, or ambiguous, and so may stand in need of clarification. And part of my aim here is to try to arrive at a somewhat clearer characterization of them. But the view about self-knowledge that they help to articulate is one that we all recognize and endorse in countless ways in our day-to-day interactions with each other.

However, the view that commonsense is right has recently been challenged by Alison Gopnik (Gopnik, 1993). Gopnik is specifically concerned to rebut claims to privileged self-knowledge of intentional states, ones which, like believing, thinking, or knowing that $p$ (for some propositional content $p$ ), relate an agent to a propositional content under an attitudinal mode. Commonsense tells us that we normal adults have privileged access to the contents of our own thoughts. But Gopnik claims that 3-year-old children do not have such privileged access. She claims that experimental evidence from the behaviour of 3-year-old and 4-year-old children supports the thesis that children undergo a major conceptual shift between the ages of 3 and 4 . This shift is marked by the acquisition of a theory of mind. Before this conceptual shift takes place, children do have psychological experiences and psychological states, but they do not comprehend the intentionality of certain of their own, and others', psychological states (specifically, their beliefs). It is only after the acquisition of a theory of mind, which enables children to comprehend the representational nature of their own and others' psychological states, that they are able to comprehend the intentionality of those states. ${ }^{3}$ Thus children before

3 So, for example, she says,

By the age of 4 or 5 , children, at least in our culture, have developed something more like a representational model of mind. Accordingly, almost all psychological functioning in 5-year-olds is mediated by representations. Desires, perceptions, beliefs, pretenses, and images all involve the same basic structure, one sometimes described in terms of propositional attitudes and propositional contents. These mental states all involve representations of reality, rather than direct relations to reality itself. Perceiving, desiring, and believing become perceiving, desiring, and believing that (1993, p. 6). 
the age of 4 do not experience intentional states as intentional states; they do not have the concept of an intentional state. For Gopnik, concepts and theory go hand in hand. So experiencing, and hence knowing, intentional states as intentional requires, and is mediated by, a theory of mind. ${ }^{4}$

The claim that knowledge of intentional states is theory-dependent is one of a number of claims associated with the view known as the 'theory theory'. Briefly put, this is the view that

...commonsense psychology, including the idea of intentionality, is a theory that explains experience and behaviour. Like scientific theories, commonsense theories are 'defeasible', that is, they are refutable and revisable. (Gopnik,1993, pp. 2-3)

According to Gopnik, we have no reason to think that beliefs that are theorydependent apply differently to the self than they do to others. And she takes the results of experimental studies on the behaviour of 3-year-old and 4-yearold children to support this view. Self-knowledge is on a par with knowledge of others, not only in that both make use of the same concepts, but also in that they have the same developmental or cognitive history (1993, p. 2). In both cases, such knowledge is mediated by one and the same theory of mind.

Gopnik takes this to mean that knowledge of intentionality is, in every case, inferential, not perceptual. ${ }^{5}$ Further, she assumes that this is true, not

There is, however, experimental evidence which seems to show that 3-year-olds comprehend the intentionality of others' mental states, but cannot articulate it or act on it in the experimental context. So, for example, when asked where Sally will look for the marble, or thinks the marble is, 3-year-olds look in the right direction. Further, if placed in an environment where the concept of belief is introduced and explained, 3-year-olds can pass the task. (See Fodor, 1992, and Peterson and Siegel, 2000.) It may be that this is also the case for the firstperson situation.

Moreover, commonsense allows that we cannot have authoritative self-knowledge of our thoughts until we have some kind of conception of thoughts. So it does not rule out the view that privileged self-knowledge requires the possession of the concept of thoughts. Commonsense also seems to allow that we can have thoughts before we have a conception of thoughts. It even seems to allow that the development of a conception of thoughts might go through various stages of muddle. So a good deal of what Gopnik is arguing depends on the question of what is involved in a 'theory of mind' over and above having the concept of mental states such as thoughts. Later I will suggest that Gopnik's view just is that the very possession of the concept of a mental state requires the possession of a 'theory' of mind, and that the mere attribution of a mental state involves attributing the concept of a mental state and hence a theory of mind. Contrast this with Stich and Nichols (1992, 1995).

5 Notice that Gopnik here seems to be equating 'non-inferential' with 'not theoretically mediated'. But if one supposes that perception is modular, one can consistently maintain both that perception involves inference and that such inference is not theoretically mediated because impenetrable to Gopnik-style theory. Thanks here to Philip Gerrans.

It is unclear whether Gopnik takes psychological experiences to be representational, hence intentional, or not. The following passages suggests not:

According to the views of Gibson and Dretske, at least some kinds of perception are not viewed as representational in the usual sense. Instead, the idea is that there is a more direct 
only of 3-year-olds, but also of older children (from around the age of four onwards) and adults. Her verdict is that the belief in direct (in the sense of non-inferential) and privileged self-knowledge is an illusion. ${ }^{6}$

In what follows, I want to accomplish two things. First, I want to consider Gopnik's attempt to use the developmental data to decide the issue both in favour of the theory theory and against the commonsense view. I shall argue that this data does not support her claim that the commonsense view is inconsistent with the theory theory. Since the case for an opposition between the commonsense view and the theory theory has not been made out, then, Gopnik needs to consider two questions separately: (a) whether the developmental data presents a problem for the commonsense view, and (b) whether it constitutes an argument in favour of the theory theory. My claim is that the answer to (a) is 'no', irrespective of what the answer to (b) is. This is one reason why Gopnik would need to argue separately from the data to the denial of the commonsense view and from the data to the truth of the theory theory.

Further, I argue that Gopnik presumes a certain perceptual model of introspective self-knowledge which leads to claims about the commonsense view that are both unnecessary and highly implausible. Her failure to see how a perceptual model of self-knowledge might be reconcilable with the commonsense view is due more to a failure to appreciate the range of models that go

causal link between the world and the mind. In Gibson's terminology, perception involves a kind of "resonance" between objects in the world and the organism; in Dretske's, information (in the technical sense) flows from the object to the organism. I suggest that 3year-olds understand all relations between the world and the mind, including those that involve beliefs, in a similar way (1993, p. 13, note 5)

where, by 'perception', Gopnik seems to mean, 'perceptual experience that bears a direct causal relation to the object of perception'.

6 It isn't obvious, even if Gopnik is right about this, that once children acquire a 'theory of mind' they must make self-attributions on precisely the same evidential basis that they make other-attributions. Further, since the experimental evidence from 3- and 4-year-olds' selfattributions concerns self-attributions of past mental states, it is not obvious, even if Gopnik is right, what this tells us about present-tense self-attributions. These points are taken up later in the text (sections 3 and 2, respectively).

There is a further complication here, and one to which we shall return (section 3). By 'direct', Gopnik seems to mean a number of things. In some places, she means 'noninferential' (1993, p. 2); at others, she clearly means 'causally direct' (1993, p. 11); and at still others, she seems to mean 'unmediated'(1993, p. 6). These conceptions of 'direct' are not equivalent to one another, yet Gopnik does not distinguish between them. Thus, for example, the fact that I perceive the apple on my desk through my eyeglasses does not thereby make my access to it causally indirect, nor does it make it inferential. But my perception is mediated by my eyeglasses. One result of conflating these different senses of 'direct' is that Gopnik assumes that if perception is direct, it is not concept-dependent, or mediated by concepts. However, it does not follow from the fact that an experience is causally direct that it is unmediated by concepts. Nor does it follow from the fact that an item of knowledge is concept-dependent that it is inferred from a theory. These points will be the focus of discussion in section 3, since they bear directly on Gopnik's claim that the theory theory is incompatible with the commonsense view. 
under the name 'perceptual' than to any inherent inconsistency between them and the commonsense view.

My first aim accomplished, I turn to the second. Here I address the question of what, exactly, the relationship is between the theory theory and the commonsense view. I spend some time disentangling various theses that the theory theory might be taken to express, and argue that the commonsense view is in fact neutral with regard to the truth or falsity of the central ones. I argue that Gopnik's failure to appreciate this can be traced to her inclination to draw a sharp distinction between phenomenological and intentional content, which in turn stems from her commitment to a particular perceptual model of self-knowledge.

Before proceeding to these sections of the paper, some preliminary issues need to be addressed. Gopnik works with a difficult and complex taxonomy of psychological phenomena, and she has quite specific views about certain contrasting pairs of notions such as 'direct/indirect', and 'perceptual/cognitive'. We need to understand the taxonomy if we are to make any progress in the debate. In section 1 below, I address these preliminary issues, and prefigure some of the claims that will be important in later sections of the paper, particularly in section 3. In section 2 I focus on my first aim. In section 3 I focus on the second.

\section{The Background}

Central to Gopnik's argument against the commonsense view is her contrast between psychological phenomena to which we have 'direct' access, and psychological phenomena to which we have only 'inferential' or 'mediated' access. Gopnik believes that, in certain cases at least, one can have non-inferential (in the sense of non-theoretically mediated) introspective access to one's own psychological phenomena; access which she describes as 'direct'. She characterizes the relevant phenomena as 'conscious experiences with a particular kind of phenomenology, the Joycean or Woolfian stream of consciousness' (1993, p. 1), and reserves the term 'psychological experiences' for them. These experiences she contrasts with psychological states, 'the underlying entities that explain behaviour and experience', whose essential characteristic is that they are intentional (1993, p. 1).

Psychological experiences are distinguishable from psychological states in two ways. First, experiences have a particular kind of phenomenology. Second, subjects have direct access to their own psychological experiences by way of having direct access to their phenomenology.

In contrast to this, subjects do not have direct access to their own psychological states. Awareness of these requires awareness of their intentionality, and this requires the application of a theory of mind to psychological experiences, 
of which one is directly aware. ${ }^{7}$ Further, although subjects believe that they experience their psychological states directly, this experience is illusory.

Thus, in Gopnik's classificatory scheme, there are three items in the psychological domain concerning which the question of whether one has 'direct and privileged' self-knowledge of them might arise. There are one's psychological states (say, one's belief that water is transparent); there are one's psychological experiences of one's psychological states (to use Gopnik's terminology, one's 'own-belief-experiences' (1993, p. 13)); and there are beliefs that one has about one's own psychological states, based, at least in part, on one's psychological experiences of those states (say, one's belief that one believes that water is transparent).

This is analogous to the case of perception, where there are also three items. First, there is the object of perception (say, the round red apple). Second, there is the perceptual experience of the object of perception (the 'round-red-appleexperience'). Third, there is the belief one has about the object of perception (the belief that there's a round red apple).

However, for Gopnik there is this important difference. In the case of perception, it is natural and correct to view the relation between the experience and its object as being direct. But this is not a viable way to view the relation between those psychological experiences that are experiences of psychological states and psychological states themselves. For Gopnik, subjects do not perceive, in any sense of 'perceive' that involves the idea of direct experience, the intentionality of their own psychological states - their representational nature. Further, since intentional psychological states have no particular phenomenology associated with them, subjects do not perceive these states.

Gopnik's view about psychological experiences involves a commitment to a particular perceptual model of introspective self-knowledge, and she assumes

\footnotetext{
7 According to Gopnik,
}

...we might construe the assertion of first-person privileged knowledge as a matter of phenomenology. It concerns the way our psychological experience feels to us. This assertion also seems incontrovertibly true (ibid., p. 1).

So the mistake commonsense makes, it seems, is not in supposing that our introspective access to our psychological experiences is direct, since that supposition is true. The mistake comes with the supposition that there is a direct link between psychological experiences and psychological states, so that introspective access to the latter is also direct.

I do not deny that there are internal psychological states; on the contrary, discovering the nature of such states is the fundamental task of psychology. ... I even suggest that there may be cases in which psychological states do lead directly to psychological experiences, cases in which there is genuine perception of a psychological state.

What I do want to argue is that intentionality is not such a case (ibid., p. 12). 
that the commonsense view is committed to it. ${ }^{8}$ But this assumption is false. What I shall argue is that there is a perceptual model of self-knowledge which does not require a rejection of the commonsense view.

\section{Does the Data Really Show that the Commonsense View is False?}

Gopnik's support for the theory theory is based on developmental data from experiments involving 3-year-old and 4-year-old children. The experiments are designed to test whether these children understand what it is to have a false belief. There are two basic types of tasks, whose failure to perform correctly by 3 -year-olds strongly suggest that they do not have the concept of false belief, and whose successful performance by 4-year-olds strongly suggests that they do have the concept of false belief. Against the background of other significant developmental data, Gopnik takes this data to show (1) that 3-year-olds do not have the concept of intentionality and so do not have self-knowledge of the intentionality of their own psychological states; (2) that 4-year-olds do have the concept of intentionality and so do have self-knowledge of the intentionality of their own psychological states, and (3) that the difference between the two consists in the construction, at some point in development between the ages of 3 and 4 , of a theory of mind by children. It is only after the construction of a theory of mind that children (hence adults) are able to have self-knowledge of the intentionality of their own psychological states. ${ }^{9}$

I cannot do justice here to the tremendous amount of literature documenting experimental studies on the cognitive development of 3- and 4-yearold children that has been cited both in support of and against Gopnik's claim in the past decade alone. However, two examples, one illustrating failure of 3-year-olds successfully to perform a particular false belief task concerning others, and the other illustrating their failure successfully to perform that same false belief task with regard to their own past psychological states, may be helpful here. The false belief task is known as the deceptive box, or unexpected

8 Thus, Shoemaker claims,

... [Gopnik] apparently thinks that just because the concepts involved in these self-ascriptions are theoretical, as in the theory theory, it cannot be the case that we directly experience our possession of the beliefs, desires, and so on, that are self-ascribed. Here, I think, we see the perceptual model of introspection at work. The assumption is that the selfascriptions must be grounded on something like sense perception, and that where claims with theoretical content are grounded on perception they cannot be direct perceptual reports and must be instead the product of some kind of inference (Shoemaker, 1993, p. 79).

9 But see Peter Carruthers (1996), who argues that it is possible for someone who believes that the concept of belief is held in place by a theory (and so is a theoretical concept) nevertheless to have a perceptual model of how first-personal attributions are actually carried out. 
contents, task (Perner et al., 1987; adapted to the first person case by Gopnik and Astington, 1988)..$^{10}$

In this experiment (Perner et al., 1987; Gopnik and Astington, 1988), a group of 3-year-olds is presented with a closed Smarties tube, and asked what they think is in the tube. They report that they think that candy is in the tube. Then the tube is opened in the presence of the children, and they are allowed to see its contents, which turn out to be pencils, not candy. They are then asked what another subject, who has not seen the opened tube, will think is in the tube when they first see it. They report that that subject will think that pencils are in the tube. This, Gopnik claims, strongly suggests that these children believe that objects and states of the world are directly (or 'transparently' (1993)) apprehended by the mind, and so don't appreciate that another person might misrepresent the world - in this case, the tube-as containing candy.

This kind of failure to appreciate that others, who are not in the same epistemic position as they themselves are in, may fail to represent the world as it is, and instead represent it as it is not, (i.e., misrepresent it) is a failure in false-belief tasks. But there is another kind of failure that 3-year-olds display of a false-belief kind which strongly suggests that these children not only fail to appreciate the intentionality of others' psychological states, but fail to appreciate the intentionality of their own psychological states. This is illustrated by a second experiment involving the deceptive box task, which differs slightly from the first.

In this second experiment (Gopnik and Astington, 1988; replicated with additional controls by Wimmer and Hartl, 1991), 3-year-olds are, as before, shown a Smarties tube and asked what they think is in the tube. They respond that they think that candy is in the tube. Then the tube is opened in the presence of the children and they are allowed to see that there are pencils, not candy, in it. Then they are asked what they thought, when they first saw the tube and before it was opened, was in the tube-a question concerning their own immediately past beliefs. $1 / 2$ to $2 / 3$ of the group consistently respond by saying that they always thought that pencils were in the tube.

This, Gopnik claims, strongly suggests that 3-year-old children are not only

10 This contrasts with a second false belief task, known as the unseen displacement, or unexpected transfer, task. Here a scene with two dolls, Maxi and his mother, is enacted in front of a child. In this scene, Maxi and his mother return home with some shopping items, and Maxi places some chocolate in a blue cupboard in the kitchen, where they both are unpacking the shopping. Then he leaves the room. In his absence, Maxi's mother removes the chocolate from the blue cupboard, uses some of it, and replaces the remainder in a different cupboard. The child is asked where Maxi will look for the chocolate when he returns to the room. Children under the age of 4 consistently say that Maxi will look in the cupboard where it now is, rather than the cupboard in which Maxi originally placed it. Children aged 4 consistently say that Maxi will look in the blue cupboard, where Maxi originally placed it (see Wimmer and Perner, 1983; Perner et al., 1987). 
unable to appreciate that another person might misrepresent the world, but that they are unable to appreciate that they themselves might misrepresent the world. For they do not recognize that their past beliefs or thoughts might be erroneous. This again supports the view that 3-year-olds do not appreciate the intentionality of psychological states. ${ }^{11}$

According to Gopnik, data of the second kind does more than this. It suggests not only that children (hence adults) need a theory of mind in order to appreciate the intentionality of others' psychological states, but that they need a theory of mind in order to appreciate the intentionality of their own psychological states. And if this is right, then the belief that one has direct, privileged awareness or knowledge of one's own intentional psychological states (as opposed to one's experiences) is false.

It is tempting to respond to this by arguing, as some (e.g., Chandler and Carpendale, 1993; Harris, 1991; Nichols, 1993) have, that the commonsense view only applies to one's current, consciously entertained states, and not to subjects' past psychological states. This seems right, even by Gopnik's own lights. The commonsense view concerns knowledge of states to which subjects can have 'direct and privileged' access. But Gopnik treats 'direct' both as equivalent to 'noninferential' and as elliptical for 'causally direct'. And knowledge of one's own past psychological states is not, in involving memory, plausibly viewed as causally 'direct'. So the commonsense view does not apply to such states, and the developmental data is consistent with it.

The fact that knowledge of the past (even one's own past psychological states) involves memory, and memory is fallible, suggests another, different response. It might be argued that 3-year-olds' failure to perform correctly on false-belief tasks with regard to what others think about a situation here and now may well be evidence that such children lack a theory of mind by which they are able to understand the intentionality of others' psychological states. But it is not evidence that these children lack a theory of mind by which they are able to understand the intentionality of their own states. This is because, in their own case, what they are being asked to do is correctly remember their own past states.

Gopnik argues, however, that this failure cannot be put down to a mere memory failure. ${ }^{12}$ For 3 -year-old children are consistently able to report their

11 But see Russell (1996) for a counter interpretation of the result that 3-year-olds don't appreciate that their past beliefs or thoughts might be erroneous in terms of an executive function/attention switching problem.

12 Goldman (1993) argues that it isn't a 'simple' memory failure, but may be a memory failure nonetheless. His claim is that results from Mitchell and Lacohee (1991) show that 3-yearolds perform significantly better on false belief tasks concerning their own past beliefs when they are given mnemonic assistance:

After children expressed their false expectation of what is in a box (e.g., candy) they selected a picture of what they thought was inside and "mailed" it. With this manipulation, 18 out of 203 -year-olds later reported correctly that they had previously thought 
past states of pretense and imagining, as well as their past desires. They do not report them inaccurately. Gopnik maintains that this is further evidence of the source of failure of 3-year-olds to accurately report their past beliefs, namely, that they cannot appreciate that their intentional psychological states might misrepresent the world (1993, p. 8). According to her, in pretense the world is not presented as being a certain way, or any way at all: children know that the banana that they are pretending is a telephone is not a telephone. Pretense is not about representing or misrepresenting the world. Similarly for imaginings, and for desires. In all of these cases, children do not need to appreciate the intentionality of their psychological states, because they can appreciate them without needing, as it were, to match them up with perceived reality with which they may conflict. ${ }^{13}$

So the response that the failure of 3-year-olds to correctly report their past beliefs is a memory failure is not an easy one to pursue. It would require a much more sophisticated argument to reconcile this with the data about past states of pretense and imagining, and past desires, in 3-year-olds. ${ }^{14}$

A much more plausible response, at least on the face of it, would be to maintain that 3-year-olds do appreciate the intentionality of their beliefs to the extent that they appreciate that they are about the world around them. ${ }^{15}$ What they lack is a complete understanding of the intentionality of their psychological states. In particular, they do not appreciate that their psychological states may misrepresent the world (i.e., represent it as it is not) as well as be about the world as it is. In other words, they do not lack a concept of intentionality altogether; they simply have an incomplete concept.

that candy was in the box, although they now knew it was pencils (Goldman, 1993a, p. 43).

Goldman takes this to support the thesis that there is an information-processing problem in 3-year-olds. It seems that the overt action of 'mailing' helped either to strengthen the memories of 3-year-olds' past beliefs or to distinguish these past beliefs from their present ones.

13 Gopnik puts this point by saying that, for 3-year-olds, there are two kinds of psychological states, 'silly states' and 'serious states'. The former include pretenses, images and dreams, whereas the latter include beliefs and perceptions. Further,

For young children, pretenses and images are unrelated to reality: They cannot be falseor true, for that matter $(1993$, p. 7$)$.

14 See also the experiments with the changes of location drawings in which children misidentify their own immediately past beliefs (BBS Symposium, 1993). Once again an executive mechanism may be involved.

15 In fact, it seems that 3-year-olds must appreciate the intentionality of their beliefs at least to this extent, if we are to make sense of the 'serious'/'silly' state distinction. Harris (1993, p. 48) suggests something along the lines of what I am suggesting here, although he does not describe it in terms of the incompleteness of a concept, and it is unclear whether he takes the conceptual difference between 3-year-olds and 4-year-olds to consist in a difference in completeness of the same concept possessed or whether he takes 3-year-olds and 4-yearolds to possess two different concepts. 
If this is right, we can agree that the problem is not one of memory. But the point that the commonsense view only applies to one's current, consciously entertained states still seems to stand. For it is possible that 3-year-olds have acquired an important part of the concept of belief, namely, that it aims at truth, without having yet acquired a firm grasp of the fact that belief aims at truth but sometimes fails to reach its target. And appreciation of this latter might be required for an understanding of misrepresentation and correspondingly of false belief. In this case, 3-year-olds might fail to distinguish the question 'What does/did X think?' from 'What is/was the thing for X to think?'. ${ }^{16}$

This suggestion has also been supported by appeal to developmental data. First, 3-year-olds are much better at reporting their own current, conscious (intentional) psychological states than they are at reporting the current, conscious states of others (Perner and Ogden, 1988; Povinelli and DeBlois, 1992; Wimmer et al., 1998a). Second, they are consistently correct in reporting their current beliefs, if not their erroneous ones of the past (Harris, 1991; Gopnik and Slaughter, 1991). ${ }^{17}$ Third, they appreciate that their psychological states are not states of the world (as evidenced, for example, by the fact that they report their imaginings as like 'making pictures' in their minds) (Estes et al., 1989; Harris, 1993). All of this indicates that, while they may not understand completely the nature of representation, they do understand the nature of intentionality. One reason for their failure to appreciate that intentional states might misrepresent may be that their first-personal present-tense experience of intentionality is first and foremost experience of their own current, consciously entertained intentional states, not of their past intentional states or the intentional states of others.

This explanation, unlike Gopnik's, makes space for the possibility that the conceptual shift that takes place between the ages of 3 and 4, while being a major one, is not an all-or-nothing affair. One can have an incomplete concept. But it also makes space for the view that subjects do at least sometimes have direct, privileged awareness of the contents of their own intentional psychological states. The commonsense view need not commit one to any claim about how privileged this awareness is, nor to any particular view as to which class of intentional states are privileged in this way. Further, it is plainly consistent with the commonsense view that authority comes in degrees, not just in the sense that at any given time a subject may be more authoritative about her present, consciously entertained intentional psychological states than

16 I owe this way of putting the point to Martin Davies.

17 It is arguable that this particular piece of evidence is not adequate to support the claim that 3-year-olds have mastered an important part of the concept of representation, since, unlike the case in which they 'imagine' situations which are alternatives to their current picture of the world, in this case they are faced with only one picture of the world, their current one. In this case, it might be argued, there isn't sufficient basis for attributing to them appreciation of the difference between their reports about their own current beliefs and reports about the world. Thanks to an anonymous referee for this point. 
those of her past, even her immediate past, but also in the sense that over time a subject may become more authoritative about certain of her intentional psychological states as a result of cognitive development. ${ }^{18}$

This alternative explanation need not be viewed as taking a stand either for or against the theory theory. For the explanation allows for the possibility that the data does favour the theory theory. What it does not guarantee is that in favouring the theory theory, the data counts against the commonsense view.

This should not surprise us. After all, the commonsense view is not committed to any developmental theory: it is only committed to the view that subjects are directly aware of the intentional contents of certain of their own intentional states, and to an asymmetry between self-knowledge and knowledge of others. How they arrive at that awareness is not part of the story. In the same way, perhaps, subjects are directly aware of the grammaticality of language (certain phrases just 'sound' wrong), but they are only aware after they acquire competence. How that competence is acquired may be inaccessible to them, but no one would deny that they are so aware on that basis. Further, it would be no objection to that story that competence comes in degrees and develops in stages. In short, applied to language, Gopnik's view sounds very implausible. ${ }^{19}$

Let us recapitulate. Two responses have been given to Gopnik's claim that the developmental data shows that the theory theory is incompatible with the commonsense view. First, whereas the developmental data concerns subjects' knowledge of their past psychological states, the commonsense view concerns subjects' knowledge of their current conscious states. So while the data may show that subjects are not authoritative with regard to knowledge of their own past psychological states, it does not show that the commonsense view is false.

Second, the developmental data is consistent with the view that 3-yearolds do have the concept of an intentional state, but that this concept is incomplete. This in turn is consistent with the commonsense view. For the claim that subjects have direct and privileged knowledge of the contents of their psychological states (of their representations) is compatible with failure to recognize that sometimes these contents can misrepresent. Indeed, the commonsense view about epistemic privilege concerns the contents of such states only; it says nothing about the epistemic status of subjects' knowledge of the truth or falsity of such contents, let alone about how that knowledge is

18 So what I have claimed so far is that the commonsense view of self-knowledge need not have a problem accounting for the developmental data that Gopnik takes to favour theory theory. But the point here is not that having a correct theory need not be an all-or-nothing affair. It is that even if the data does favour the theory theory, it does not count against the commonsense view. Gopnik's belief that it does is based on an equation of concept and theory, and it is this equation that I want to contest.

19 Thanks to Philip Gerrans for suggesting the analogy.

(C) Blackwell Publishers Ltd. 2002 
acquired. This being so, it does not extend to knowledge that a content misrepresents.

Gopnik supposes that adopting an explanation in terms of the commonsense view must involve taking a stand against the theory theory only because she conceives of the commonsense view as committed to a particular version of the perceptual model of self-knowledge. According to this, in perception one is directly aware of the objects of perception in the sense that one's awareness is non-conceptual and non-intentional. Given that self-knowledge of one's own intentional states requires being aware of such states as intentional states and so requires possession of the concept of intentionality, by Gopnik's lights, it requires possession of a theory. In possessing such a concept, one thereby possesses a theory. In being theory-dependent, self-knowledge is inferential, indirect. Direct awareness, as in perception and sensation, does not involve being aware of the object of one's awareness as one thing or another, or as anything at all.

However, this is not the only, nor the most plausible model of perception on which to base an account of introspective self-knowledge. ${ }^{20}$ As Gopnik herself seems to recognize, there are perceptual models according to which, in perception, one is aware of a thing as something or other, which requires possession of concepts. She recognizes, for example, that perception can be understood 'transparently' (as simply 'seeing x', for some object or state of affairs $\mathrm{x}$ ), or as '....mediated by representations or propositions' (as in perceiving or seeing that something is the case) (cf. 1993, p. 6). But she doesn't seem to recognize that the relevant analogy between self-knowledge and perception might employ a notion that falls somewhere in-between these two: a notion of 'seeing as', that might signal the concept-dependence of perception and so its intentional nature without thereby construing it as fully propositional, as beliefs are typically taken to be (McDowell, 1994; Brewer, 1999). One way of putting this view is to say that perceptual experience is a matter of seeing as in the sense that, when a subject has such an experience, she takes an object $X$ to have some property or other. She does so because the content of her experience represents the world around her as being some way or other.

To accept a view like this is not necessarily to deny that there is much that we see that we do not take ourselves to see. But it is to deny that the idea that in perception we do not take an object $X$ to be any way at all is a genuine possibility. As Heil puts the point:

20 I am assuming here for the sake of argument that the commonsense view is actually committed to a perceptual account of how such access is achieved. My own view is that a 'quasi'perceptual account of certain core cases of self-knowledge, namely, knowledge of one's current conscious thinkings, is both viable and defensible (Macdonald, 1995, 1998a and 1998b). However, the argument in this paper does not depend on accepting that view. 
...it is easy to imagine cases in which, for any given property, $P$, possessed by $X, S$ sees $X$ without taking $\mathrm{X}$ to have $P$. And we might describe such cases as ones in which $S$ fails to see $X$ under a certain aspect. On the other hand, the plausibility of these cases may well rest at least in part on the tacit assumption that $X$, if not seen under this aspect, is seen under some other aspect, if not taken to have $P$, then taken to have some other property, $P^{\prime}$..... seeing tout court requires that there be cases in which $S$ encounters $X$ perceptually, but does not take $X$ to be any way at all. It is far from clear, however, that there are any such cases...(1991, p. 8).

Heil's claim is that whatever 'perceptual experience' is, for human beings anyway, it is doubtful that it is completely unconceptualized, 'nonepistemic' perception. ${ }^{21}$

An account of introspective self-knowledge based on a more robust perceptual model can accommodate both the idea that such knowledge requires awareness of one's own intentional states as intentional states and the idea that such knowledge can be direct - as direct as is perception itself. The need to appeal to the theory theory to explain self-knowledge of one's intentional states as intentional states (as about things and phenomena in the non-mental world) is thereby made redundant.

This alternative explanation is preferable because it avoids commitment to a counterintuitive view about how children understand their own intentional psychological states, namely, that they do so by virtue of constructing a theory of mind which they are then able to apply to them. At the same time, it leaves those who do favour the theory theory free to endorse the commonsense view. So there is nothing to be lost, and much to be gained, by rejecting the perceptual model on which Gopnik's reasoning is based.

Let me be clear about what I am and what I am not saying here. I am not saying that Gopnik is correct in her view that having a concept of intentionality does involve knowing a theory, but somehow the theory does not have to be involved epistemologically and so does not introduce any indirectness. I am saying that, in Gopnik's sense of 'theory', which assumes that a theory requires a set of causal laws by which deductive-nomological explanations can be

21 The distinction between 'epistemic' and 'nonepistemic' perception is familiar from the work of Fred Dretske, and Gopnik notes this when associating herself with Dretske and Gibson in taking 'perception' to involve only 'nonepistemic' perception. What she endorses in doing this is the claim that perceptual experience is non-conceptualized, non-intentional, non-belief-dependent. Whether it is non-representational is a more subtle matter, and one that I shall not address here. What matters for present purposes is that both Gibson and Dretske draw a sharp distinction between experience and belief, and consider the former to be independent of the latter. This distinction is highly controversial, however, amongst both philosophers and psychologists. It informs Gopnik's thinking in a way that does injustice to current and historical views about the nature of perception itself. 
effected, I disagree that having a concept of intentionality involves knowing a theory. ${ }^{22}$ I agree with Gopnik that children need to have developed concepts of beliefs and the like in order to understand their own intentional psychological states. But I think it no more plausible to maintain that possession of concepts of belief and the like requires possession of a theory of intentionality than it is to maintain that possession of a colour concept (also a 'folk' concept) such as red requires a theory of colour (complete with causal laws by which to predict and explain colour phenomena). And I take it that it is not plausible to maintain the latter. So I deny that developing an interconnected network of concepts amounts to developing knowledge of a theory, in Gopnik's robust sense of 'theory'. ${ }^{23}$ A fortiori, I deny:

...that children construct a coherent, abstract account of the mind which enables them to explain and predict psychological phenomena. Although this theory is implicit rather than explicit, this kind of cognitive structure appears to share many features with a scientific theory. Children's theories of the mind postulate unobserved entities (beliefs and desires) and laws connecting them, such as the practical syllogism. Their theories allow prediction, and they change (eventually) as a result of falsifying evidence. ...Moreover, the child's theory of mind is equally applicable to the self and to others. (1993, p. 10)

\section{What Exactly is the Relation between the Theory Theory and the Commonsense View?}

Suppose, then, that the developmental data presents no problem for the commonsense view. What exactly is the relation between that view and the theory theory? In order to answer this, we need to know more about the central claims of the latter. From our discussion of Gopnik's views, we know that

22 Further, I would deny the assumption, which Gopnik also seems to make, that inference requires the possession and use of a theory in her sense of 'theory', either explicitly or implicitly. For more on the rejection of this assumption, see Robert Brandom (1998).

23 So I do not see myself as necessarily in disagreement with those who, like Carruthers, claim that the concept of belief is theory-embedded. Carruthers maintains that psychological concepts such as that of belief is determined by the position or role they play in a folkpsychological theory of the mind (structure and function). He denies that grasp of such a theory involves being a 'little scientist', however, and so distances himself from the claims made by Gopnik on behalf of the theory theory with regard to children. In the weaker and more general sense of 'theory' according to which children before the age of 4 possess one, I am less unsympathetic to the view that concept and theory go hand in hand. Further, in this sense, it is possible to hold, as Carruthers argues, that theory possession does notentail epistemic indirectness - at least no more so than does perception itself (1996, p. 26). What he means here is that it need not involve any conscious, personal-level inferences. This is consistent with my view. 
one such claim is that subjects' understanding or knowledge of others' psychological states is in some way mediated by a theory of mind. 'Understanding or knowledge' seems to mean, not the mere attribution of mental states to others, but the explanation of mental states, or the activity of predicting what mental states another will be in.

A fruitful way to flesh this claim out is in terms of the way in which the theory theory accounts for our 'folk' psychological practice (Davies and Stone, 1996). From a very early age, we are remarkably competent at attributing mental states to others, and at predicting and explaining their mental states and behaviour by this means. There seem to be three aspects of or threads to this practice: describing others in terms of mental states, explaining others' mental states and behaviour by means of such descriptions, and predicting others' mental states and behaviour using these descriptions. A key commitment of the theory theory is to account for the psychological practice of predicting others' mental states. It claims to do this by appeal to the thesis that predicting others' mental states requires the possession and application of a theory of mind.

Theory theorists differ amongst themselves on their views as to the nature of such a 'theory'. Some, like Gopnik, think that it is characterized by principles which take the form of universal causal laws, and that understanding one's own and others' psychological states involves the application of such laws to data, i.e., psychological experiences and behaviour (Gopnik, 1993; Gopnik and Meltzoff, 1997; Perner and Ogden, 1988; Perner, 1991). These people think of scientific theories as the paradigmatic example of theories. Others (e.g. Stich and Nichols, 1995a, 1995b) think that almost any set of generalizations of the 'folk' sort constitutes a theory of mind. Since most adults, as well as most children, are not generally able to verbalize explicitly causal 'laws' of a theory of mind understood in the first way, those who conceive of a theory of mind in the quite strict sense associated with such laws commonly claim that subjects implicitly, rather than explicitly, possess a theory of mind. ${ }^{24}$

How much does this tell us about the compatibility or otherwise of the theory theory with the commonsense view? It tells us very little. The commonsense view is first and foremost a view about the epistemology of self-under-

24 For the purposes of distinguishing the theory theory from the simulation theory, the difference between the stronger sense of 'theory' associated with scientific theories and the weaker sense of 'theory' by which almost any set of generalizations of a 'folk' sort counts as a theory does not matter. But of course it does matter for the purposes of reconciling the commonsense view with the theory theory. If the weaker sense is at issue, it is far easier to see how the theory theory might be reconciled with the commonsense view, since perception itselfwhat Gopnik takes to be a paradigmatic case in which one has direct and privileged selfawareness - might on this weak sense be viewed as theory-laden and so conceptual.

Another issue that divides theory theorists from one another is whether the theory of mind is innate or learned. Some, such as Gopnik, hold that it is learned, but others, such as Baron-Cohen, hold that at least some of it is innate. Again, this is an issue concerning which we need not adjudicate here. 
standing or self-ascription. Of course, any view about the epistemology of self-understanding is likely to have some implications for cognition. But these implications are not all that apparent or direct. For on at least one understanding of it, the theory theory is not primarily a theory about the epistemology of self-knowledge and knowledge of others; on what justifies claims to selfknowledge and knowledge of others. It is a theory about the nature of mental concepts. It says that mental concepts are theoretical concepts. Viewed in this way, there is no immediate inference from the adoption of the theory theory to the truth or otherwise of the commonsense view, even if we suppose, with Gopnik, that mental concepts are theoretical concepts because of how they are constructed. This is because there is important distinction to be drawn, concerning the epistemology of mental state attribution, about how it is that judgements arrived at by a given methodology amount to knowledge, when they do.

Further, there is a distinction to be drawn between what is involved in grasp of mental concepts and what is involved in making predictions and explanations. This distinction concerns the methodology of mental state attribution, of how we go about making judgements about our own and others' mental states. Viewed as a claim about our grasp of mental concepts, the theory theory may say only that grasping a concept is knowing a theory. ${ }^{25}$ This need not involve any claims about how we predict and/or explain the mental states of others. It may be that grasping a concept is knowing a theory, but that when it comes to prediction and explanation of others' mental states, we use simulation as our method. Perhaps the opposite is true: that our grasp of mental concepts is achieved in a simulation-theoretic way (e.g., one grasps mental concepts by simulating in oneself the states (of oneself) that fall under those concepts), but that when it comes to predicting and explaining the mental states of others, a theory is called upon.

Gopnik asserts that the theory theory is incompatible with the commonsense view. But, viewed as a theory about what is involved in grasp of mental concepts, it seems to be silent on the methodology or epistemology of selfknowledge. Suppose that it is true that mental concepts are defined by their theoretical role in a theory of mind, a theory about 'what beliefs (etc.) really are', to use Gopnik's terminology (1993, p. 95). Then they are constituted by the role that they play in such a theory, usually conceived by theory theorists to be some sort of functionalist theory. Functionalism, in the form that is relevant to this discussion, is the thesis that the nature of a mental state, say, a belief that water is transparent, is defined by the causal relations that it is apt to bear to environmental stimuli, or input, other mental states, and behavioural

25 For the purposes of theory theorists, I think that this involves commitment not only to the view that concepts are theory embedded, but to the stronger view that concepts are individuated by the theories in which they are embedded, so that grasp of the same concept requires possession of the same theory. 
responses, or output. ${ }^{26}$ Thus, the concept of a belief, say, that water is transparent, is the concept of a state which is apt to be caused by certain environmental stimuli and other mental states, and to cause other mental states and behavioural output.

This is a view to which Gopnik (1993, pp. 44-5) has expressly committed herself. However, viewed in this way, the theory theory has nothing to say about the epistemic means by which one is justified in knowing one's own states, nor about the methodology by which one grasps one's own states. For it is compatible with a functionalist account of the nature of mental states, say, sensations, that such states are known or are knowable in ways other than by their causal roles. Specifically, they may be known or be knowable in terms of their phenomenological features, on the basis of how they feel. Similarly, observable properties, like colours, may be known by subjects on the basis of how they look, although the natures of these properties may consist in what is the best opinion of normal subjects in normal conditions. ${ }^{27}$

Thus, the theory theory may be consistently combined with the commonsense view in one or the other of the following two ways, depending on whether one considers the phenomenological aspects of one's psychological states to be functionally definable. First, one might maintain that the relation between the phenomenological features of the states of which one is introspectively aware and their causal roles is relevantly like the way in which a symptom is related to whatever it is a symptom of (e.g., a disease), viz. as reliably (perhaps even nomologically) causally related. As Sterelny puts the point:

I think a better strategy is to sharply distinguish the constitutive from the epistemic. What an elephant is is one thing; how to recognize elephants is another. No doubt there are trunkless elephants, and trunked nonelephants. But if you are confronted with a trunk you will not go far astray in supposing it comes with an elephant attached. An agent might thus recognize creatures via this symptom of elephanthood whether or not they had a complex understanding of what it was to be an elephant, whether or not this symptom is even part of what being an elephant is (1993, pp. 81-2).

Note here that, because the relationship between the symptom and what it is a symptom of is conceived of as contingent, a subject's introspective awareness of her own psychological states could mislead her as to their natures. And this would make her knowledge of her own intentional states fallible even if privileged. Nevertheless, the direct and privileged nature of such knowledge would remain intact.

\footnotetext{
26 People will recognize this as a version of the functional specification theory. (See, for example, Lewis, 1972.)

27 For an account like this see Johnston (1992, 1993).
} 
A second way in which the theory theory might be reconciled with the commonsense view is by insisting that the phenomenological features by which subjects introspectively know their own psychological states can themselves be captured in the functional definitions by which their causal roles are specified (Shoemaker, 1984). In the case of sensations, for example, one might insist that functionalism is able to account for the phenomenological aspect of a sensation, say, the painfulness of a pain, by taking it to be part of the causal role of pain to cause the belief that one is hurting, to cause aversive behaviour with respect to the source of the pain, and so on. If the phenomenological aspects of sensations are themselves functionally definable, then it is not possible to misidentify a state introspectively by identifying its phenomenological aspect, for that aspect is part of its nature. Nor need that aspect be identified introspectively by its causal role. Just as a subject might perceive the redness of an apple without grasping the causal role it plays with regard to perceivers, which role may constitute its nature, a subject might introspect the phenomenological aspect of her sensation state without introspecting the causal role which constitutes its nature. ${ }^{28}$

This strategy will only work for intentional states if at least some of these states have phenomenological features. But it may not be altogether implausible to think that at least some of these-such as current, conscious thinkings, imaginings, and pretendings - do have such phenomenological features, and have them in virtue of their contents (cf. Goldman, 1993).

The claim that there is a distinctive phenomenological aspect to the contents of current conscious thinkings, and so to at least some intentional states, is consistent with the commonsense view. But Gopnik does not appreciate this because she associates 'phenomenological' with 'direct' and 'direct' with 'non-conceptualized'. However, suppose, as I have suggested, that current conscious thinkings have both a phenomenological and a contentful representational aspect. Then, on Gopnik's conception of the commonsense view, which severs the phenomenological from the intentional features of intentional states, we seem to be forced to choose between the two in accounting for direct and privileged self-knowledge of such states. And this is just what Gopnik does. She supposes that one can be directly aware of one's own states by, and only by, being aware of a phenomenological content. The result is that direct awareness of one's intentional states is compatible with failure to know those states as intentional states. But the commonsense view does not commit one to anything so strong as this. It is compatible with the commonsense view that subjects know their own intentional states as intentional states.

28 This way of reconciling the commonsense view with the theory theory is predicated on the view that the theory theory is a theory about grasp of mental concepts. It will not satisfy theory theorists (such as Stich and Nichols) who view the theory theory as a theory about how predictions about and explanations of mental states are actually made. 


\section{Conclusion}

I have argued that Gopnik's claim that the theory theory is incompatible with the commonsense view of self-knowledge is false for two reasons. First, the developmental data, while perhaps favouring the theory theory, does not rule out the commonsense view. Second, Gopnik basis her claim about the commonsense view on a crude perceptual model of self-awareness, one which could not support the commonsense view. It is that model which is faulty, and which is ultimately responsible for Gopnik's claim that, in order for subjects to be aware of their intentional states as intentional states, they must acquire a theory of mind by which to infer that their states are intentional. Without this model of perception in place, there is no reason to think that knowing one's own states as intentional states requires the acquisition of a theory of mind.

Further, the commonsense view is neutral as between the theory theory and other theories of mind. For the theory theory is not primarily an epistemological theory about the basis for knowledge of minds, one's own or others. Thus, its relation to the epistemology of self-knowledge is neither obvious, nor direct.

Department of Philosophy

University of Canterbury

\section{References}

Bartsch, K. and Estes, D. 1993: Are false beliefs representative mental states? Behavioral and Brain Sciences, 16 (Open Peer Commentary), 30-1.

Brandom, R. 1998: Making It Explicit: Reasoning, Representation, and Discursive Commitments. Cambridge: Harvard University Press.

Brewer, B. 1999: Perception and Reason. Oxford: Oxford University Press.

Carruthers, P. 1996: Simulation and self-knowledge: A defence of theory-theory. In P. Carruthers and P. Smith (eds), Theories of Theories of Mind. Cambridge: Cambridge University Press, 22-38.

Chandler, M. and Carpendale, J. 1993: The naked truth about first-person knowledge. Behavioral and Brain Sciences, 16 (Open Peer Commentary), 36-7.

Davies, M. and Stone, T. (eds.) 1995a: Mental Simulation: Evaluations and Applications. Oxford: Basil Blackwell.

Davies, M. and Stone, T. (eds.) 1995b: Folk Psychology: The Theory of Mind Debate. Oxford: Basil Blackwell.

Davies, M. and Stone, T. 1996: The mental simulation debate. In P. Carruthers and P. Smith (eds.), Theories of Theories of Mind. Cambridge: Cambridge University Press, 119-37.

Dretske, F. 1969: Seeing and Knowing. London: Routledge and Kegan Paul.

Dretske, F. 1978: The role of the percept in visual cognition. In W. Savage (ed.), 
Perception and Cognition: Issues in the Foundations of Psychology. Minneapolis: University of Minnesota Press.

Dretske, F. 1979: Simple seeing. In D. Gustafson and B Tapscott (eds), Body, Mind, and Method. Cambridge, Mass.: MIT Press.

Dretske, F. 1995: Naturalizing the Mind. Cambridge, Mass.: MIT Press.

Estes, D., Wellman, H.M. and Woolley, J.D. 1989: Children's understanding of mental phenomena. In H. Reese (ed.) 1989: Advances in Child Development and Behavior 21. New York: Academic Press, 41-87.

Fodor, Jerry 1992: A theory of the child's theory of mind. Cognition, 44, 283-96.

Goldman, A. 1993: The psychology of folk psychology. Target article, Behavioral and Brain Sciences, 16, 15-28.

Goldman, A. 1993a: Competing accounts of belief-task performance. Behavioral and Brain Sciences, 16 (Open Peer Commentary), 43-4.

Gopnik, A. 1993: How we know our minds: The illusion of first-person knowledge of intentionality. Target article, Behavioral and Brain Sciences, 16, 1-14. (Open Peer Commentary and Author's Responses, same volume, 29-113.)

Gopnik, A. and Astington, J.W. 1988: Children's understanding of representational change and its relation to the understanding of false belief and the appearancereality distinction. Child Development, 59, 26-37.

Gopnik, A. and Meltzoff, A. 1997: Words, Thoughts, and Theories. Cambridge, Massachusetts: MIT Press.

Gopnik, A. and Slaughter, V. 1991: Young children's understanding of changes in their mental states. Child Development, 62, 98-110.

Harris, P. 1991: The work of the imagination. In A. Whiten (ed.), Natural Theories of Mind. Oxford: Basil Blackwell, 283-304.

Harris, P. 1993: First-person current. Behavioral and Brain Sciences, 61 (Open Peer Commentary), 48-9.

Heil, J. 1991: Perceptual experience. In B. McLaughlin (ed.), Dretske and His Critics. Oxford: Basil Blackwell, 1-16.

Johnston, M. 1992: How to speak of the colors. Philosophical Studies, 68, 221-63.

Johnston, M. 1993: Objectivity refigured: Pragmatism without verificationism. In J. Haldane and C. Wright (eds.), Reality, Representation and Projection. Oxford: Oxford University Press, 85-130.

Lewis, D. 1970: How to define theoretical terms. Journal of Philosophy, 67, 427-46.

Loar, B. 1993: Functionalism can explain self-ascription. Behavioral and Brain Sciences, 16 (Open Peer Commentary), 58-60.

Macdonald, C. 1995: Externalism and first-person authority. Synthese, 104, 99-122.

Macdonald, C. 1998a: Self-knowledge and the 'inner eye'. Philosophical Explorations, 1, 83-106.

Macdonald, C. 1998b: Externalism and authoritative self-knowledge. In C. Wright, B. Smith, and C. Macdonald (eds.), Knowing Our Own Minds. Oxford: Oxford University Press, 123-54.

McDowell, J. 1994: Mind and World. Cambridge, Mass.: Harvard University Press.

Mill, J.S. 1989: On liberty. In S. Collini (ed.), J.S. Mill On Liberty with The Subjection of Women and Chapters on Socialism. Cambridge: Cambridge University Press, 1-115. 
Mitchell, P. and Lacohee, H. 1991: Children's early understanding of false belief. Cognition, 39, 107-27.

Nichols, S. 1993: Developmental evidence and introspection. Behavioral and Brain Sciences, 16 (Open Peer Commentary), 64-5.

Perner, J. 1991: Understanding the Representational Mind. Cambridge, Massachusetts: MIT Press.

Perner, J., Leekam, S. and Wimer, H. 1987: 3-year-olds' difficulty understanding false belief: Cognitive limitation, lack of knowledge or pragmatic misunderstanding. British Journal of Developmental Psychology, 5, 125-37.

Perner, J. and Ogden, J.E. 1988: Knowledge for hunger: Children's problem with representation in inputing mental states. Cognition, 29, 47-61.

Peterson, C. \& Siegal, M. 2000: Insights into theory of mind from deafness and autism. Mind \& Language, 15, 123-45.

Povinelli, D.J. and DeBlois, S. 1992: Young children's understanding of knowledge formation in themselves and others. Journal of Comparative Psychology, 106, 228-38.

Pylyshyn, Z. 1984: Computation and Cognition. Cambridge, Massachusetts: MIT Press.

Russell, J. 1996: Agency: Its Role in Mental Development. Hove: Erlbaum (UK) Taylor \& Francis.

Shoemaker, S. 1993: Special access lies down with theory-theory. Behavioral and Brain Sciences, 16 (Open Peer Commentary), 78-9.

Sterelny, K. 1993: Categories, categorisation and development: Introspective knowledge is no threat to functionalism. Behavioral and Brain Sciences, 16 (Open Peer Commentary), 81-3.

Stich, S. and Nichols, S. 1992: Folk psychology: Simulation or tacit theory? Mind E Language, 7, 35-71. Reprinted in M. Davies and T. Stone (eds), Folk Psychology: The Theory of Mind Debate. Oxford: Basil Blackwell, 123-58.

Stich, S. and Nichols, S. 1995: Second thoughts on simulation. In M. Davies and T. Stone (eds), Mental Simulation: Evaluations and Applications. Oxford: Basil Blackwell, 87-108.

Wimmer, H. and Hartl, M. 1991: The cartesian view and the theory view of mind: Developmental evidence from understanding false belief in self and other. British Journal of Developmental Psychology, 9, 125-28.

Wimmer, H., Hogrefe, G.J. and Perner, J. 1998: Children's understanding of informational access as a source of knowledge. Child Development, 59, 386-96.

Wimmer, J. and Perner, J. (1983): Beliefs about beliefs: Representation and constraining function of wrong beliefs in young children's understanding of deception. Cognition, 13, 103-28. 